\title{
Notes on the vocalizations of Lemon-rumped Tanager (Ramphocelus icteronotus)
}

Peter Boesman

In the following we briefly analyze and compare voice of Lemon-rumped Tanager (Ramphocelus icteronotus) with Flame-rumped Tanager (R. flammigerus). We also try to quantify the extent of any vocal differences using the criteria proposed by Tobias et al. (2010), as a support for taxonomic review. We have made use of sound recordings available on-line from Xeno Canto (XC).

An overview of vocalizations, illustrated with sonograms:

\section{R. icteronotus}

* dawn song is a long series of well spaced phrases consisting of 1-2 rather unmelodious notes:

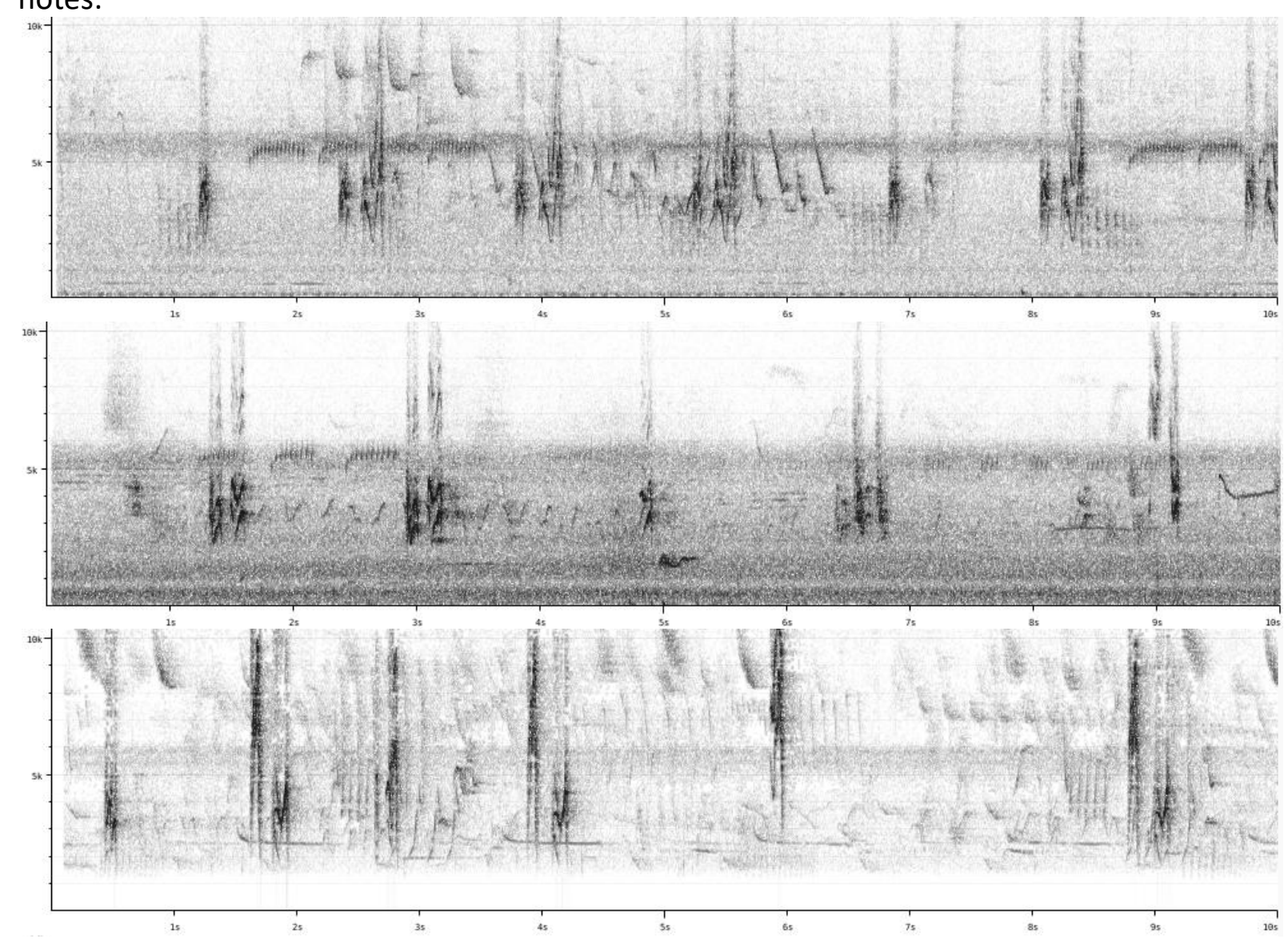


* 'day-time song' is a somewhat more elaborated phrase, usually descending in pitch, repeated:

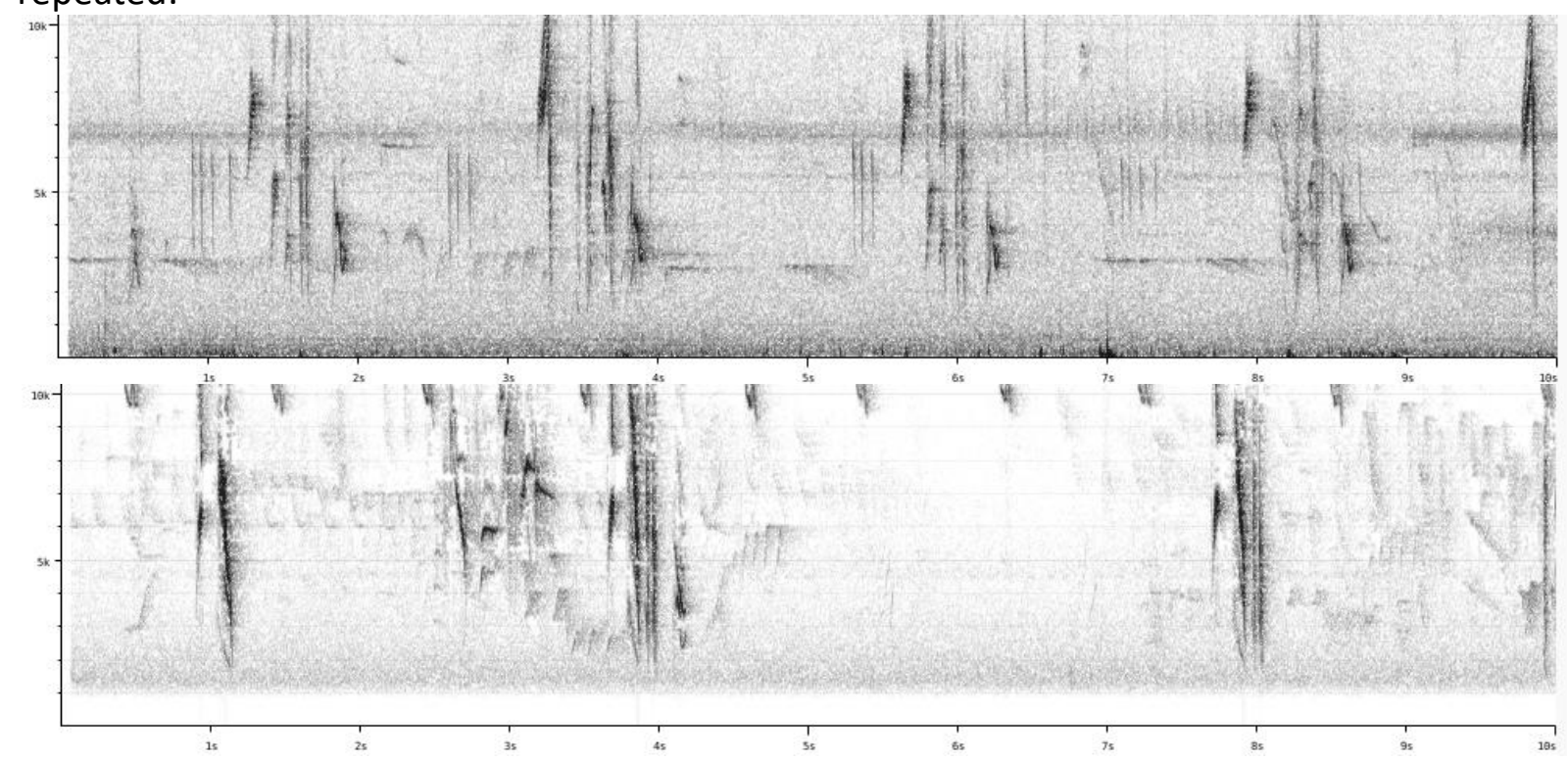

* call
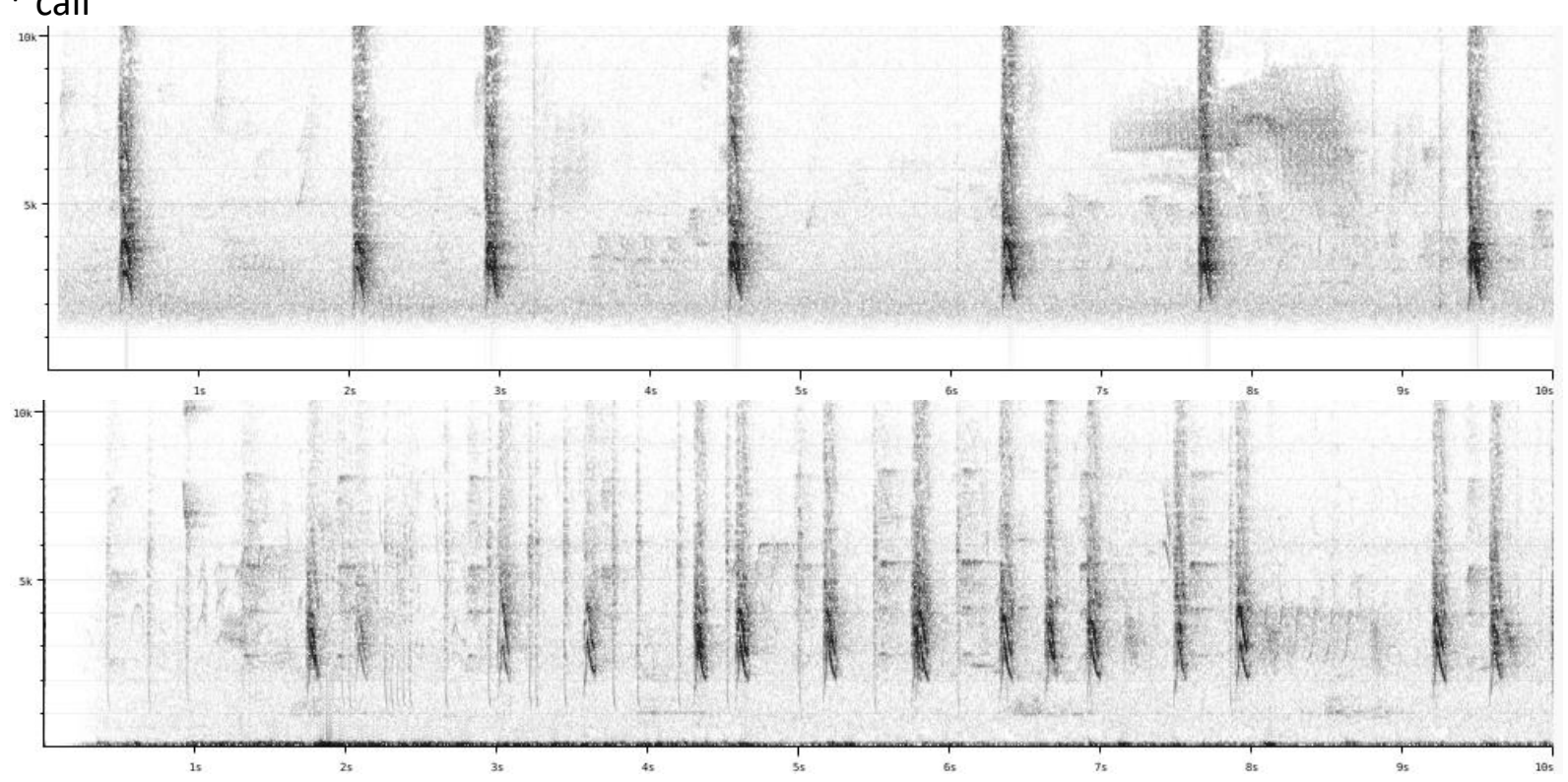

R. flammigerus

* dawn song: no recordings

* 'day-time song': no recordings 


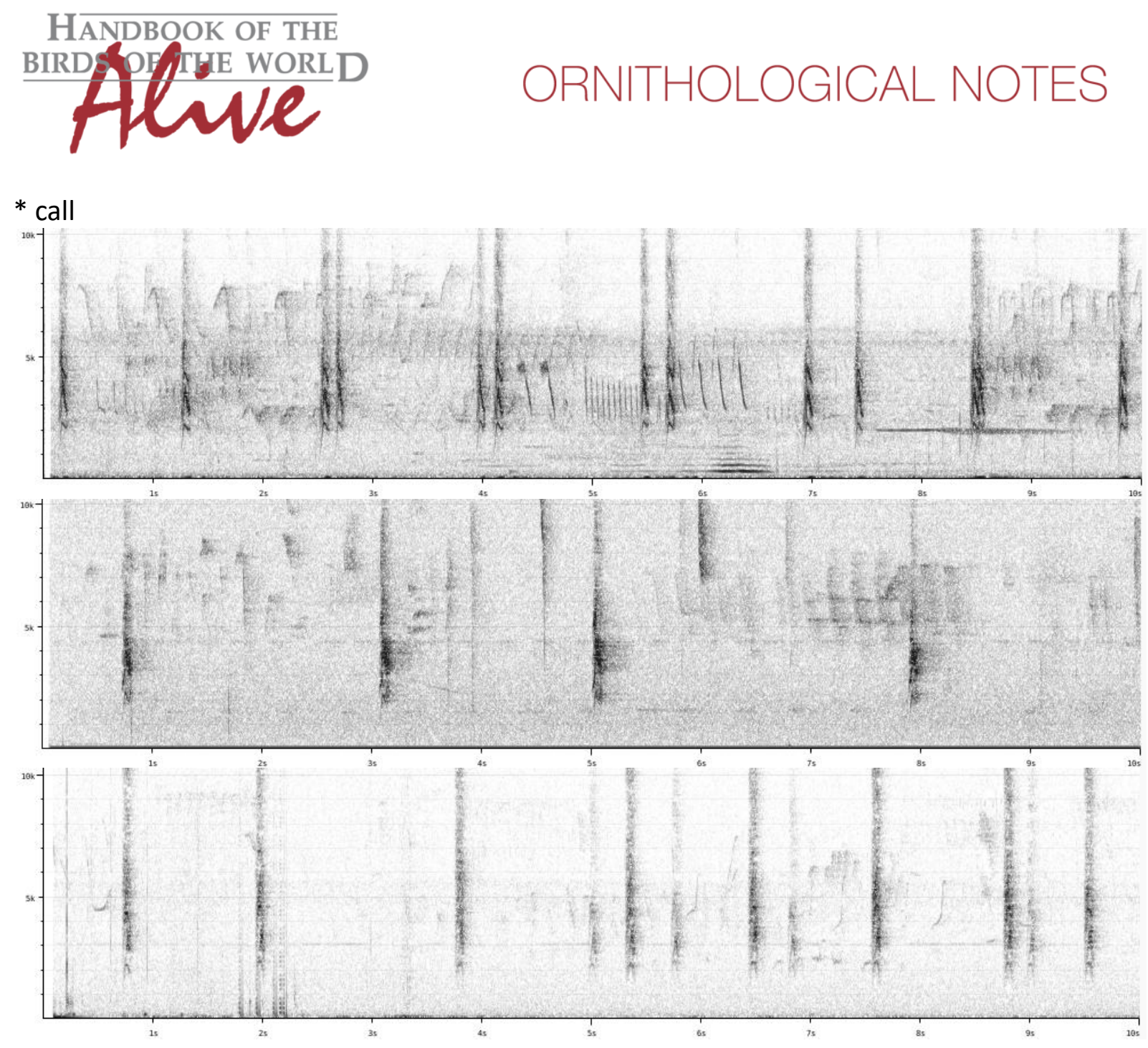

Due to lack of recordings of dawn song in $R$. flammigerus, we can only compare the main call notes (dawn song is described in HBW as an energetic series of mostly 2-note or 3-note phrases repeated over and over vs typically a 1-2-note phrase for icteronotus. Not much more can be said without recordings).

While call notes of both species look similar, there seem to be some differences:

In icteronotus from Ecuador, call note is seemingly a polyphonic note. On a sonogram, at the low frequency side, this is reflected by an overslurred note with max. freq. $c 3 \mathrm{kHz}$ and another one with max. freq. $c 4 \mathrm{kHz}(\mathrm{n}=8)$
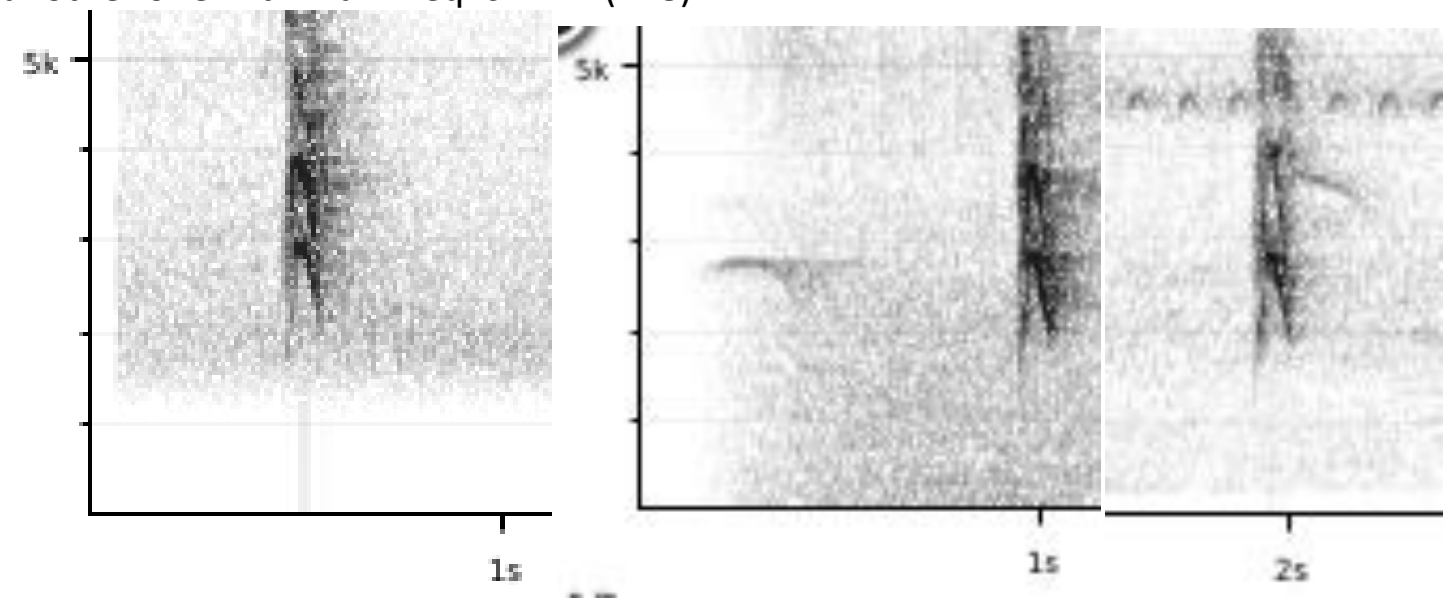


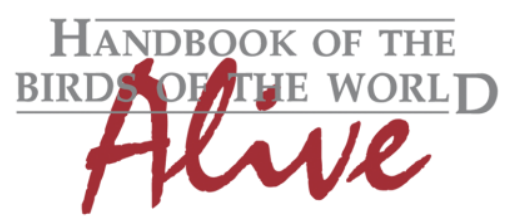

\section{ORNITHOLOGICAL NOTES}

In Colombia, there are much less recordings available, and we have only looked at those well away from the region of flammigerus, from which little can be concluded.

In Panama, note is structurally similar, but apparently overslurred notes somewhat lowerpitched.
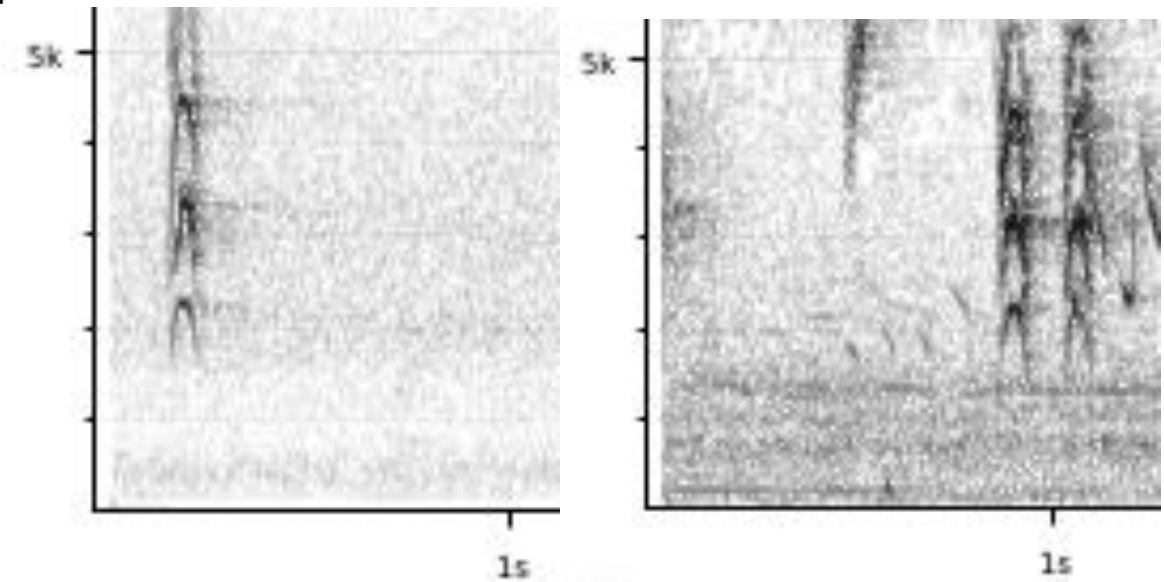

In flammigerus, main call note is structurally similar, and quite similar to above recordings from Panamanian birds (although with some examples having slightly different note shape):
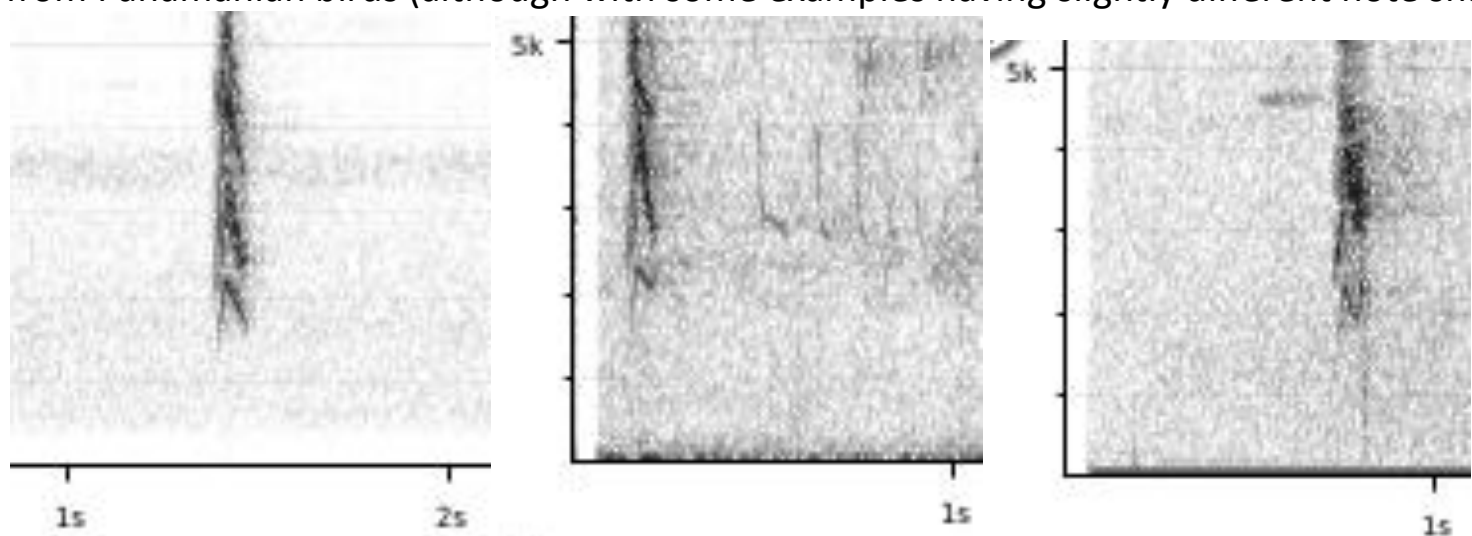

It would thus seem that call differences have rather a regional nature, with birds from Ecuador uttering slightly higher-pitched notes.

As a final remark, we may also look at dawn song of closely-related $R$. costaricensis:
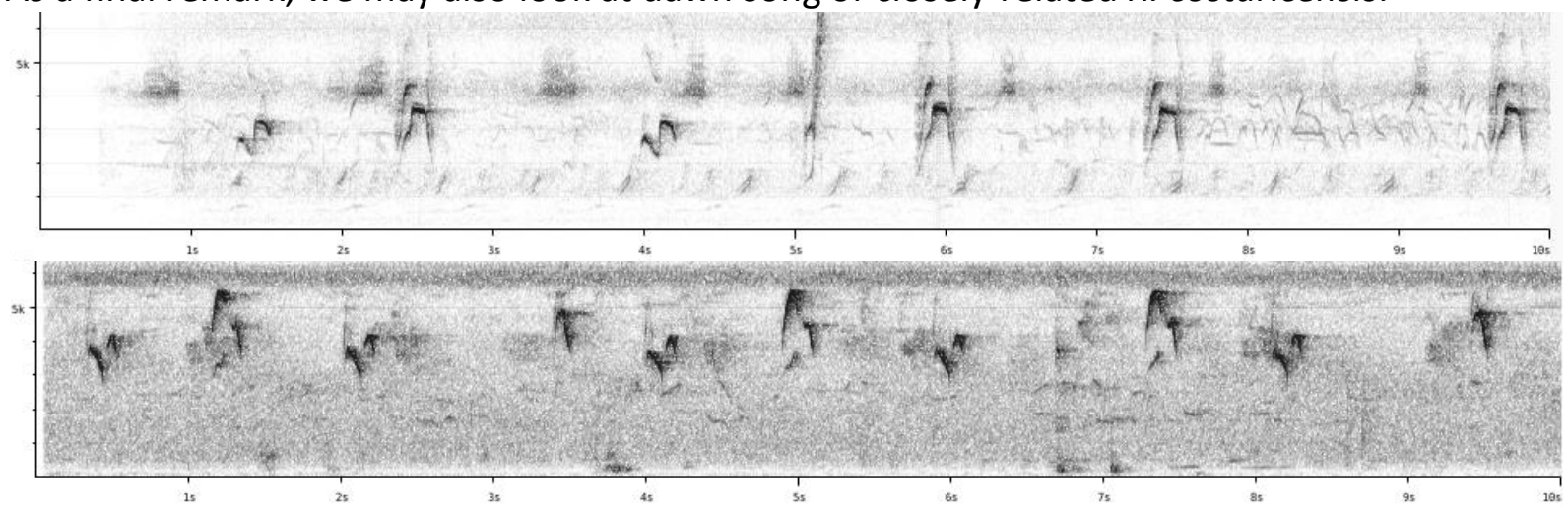

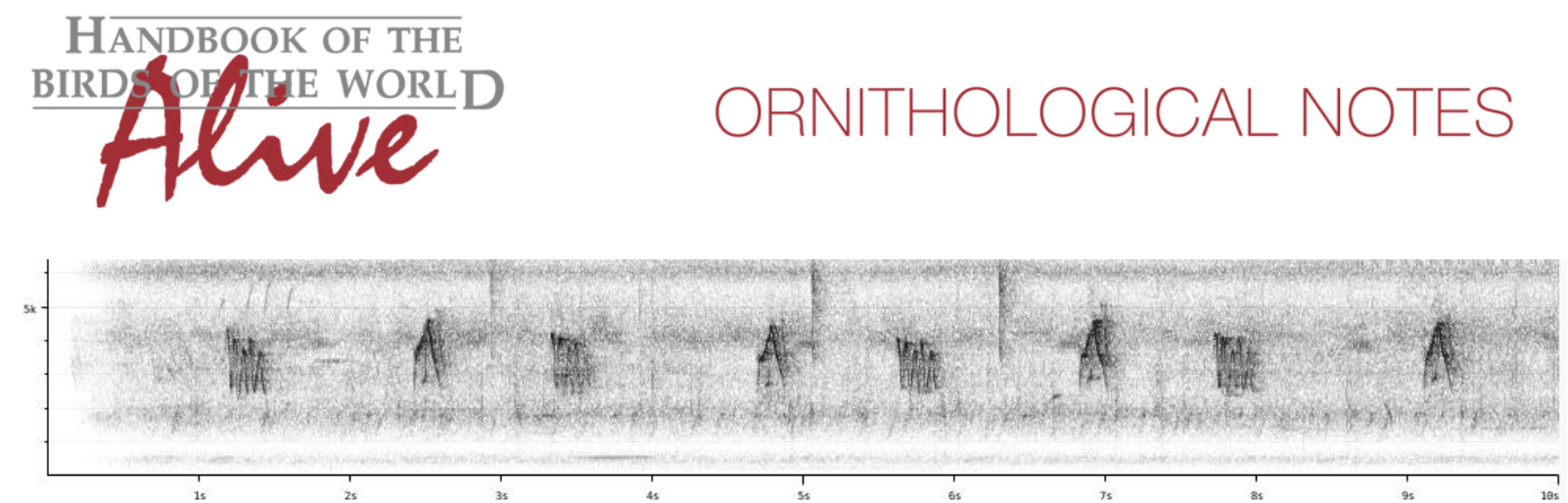

This dawn song is VERY different from $R$. icteronotus (consisting of more slurred, melodious phrases), which suggests that knowledge of the dawn song of flammigerus is really required to draw any reliable conclusions about vocal differences.

This note was finalized on 19th October 2016, using sound recordings available on-line at that moment. We would like to thank in particular the many sound recordists who placed their recordings for this species on XC.

\section{References}

Tobias, J.A., Seddon, N., Spottiswoode, C.N., Pilgrim, J.D., Fishpool, L.D.C. \& Collar, N.J. (2010). Quantitative criteria for species delimitation. Ibis 152(4): 724-746.

\section{Recommended citation}

Boesman, P. (2016). Notes on the vocalizations of Lemon-rumped Tanager (Ramphocelus icteronotus). HBW Alive Ornithological Note 441. In: Handbook of the Birds of the World Alive. Lynx Edicions, Barcelona. (retrieved from http://www.hbw.com/node/1287372 on 9 December 2016). 